\title{
Delayed latencies of auditory evoked potential P300 are associated with the severity of Parkinson's disease in older patients
}

\author{
0 atraso das latências do potencial evocado auditivo P300 está associado à gravidade da \\ doença de Parkinson em pacientes mais velhos
}

Marcia da Silva Lopes ${ }^{1}$, Ailton de Souza Melo ${ }^{1}$, Ana Caline Nóbrega ${ }^{2}$

\begin{abstract}
Electrophysiological methods could provide important information about the neurophysiological status in Parkinson's disease (PD). Objective: To investigate the prolonged auditory P300 latency in PD and its association with the disease clinical stage. Method: Clinical profiles of 44 patients were evaluated and those in initial and advanced stages of PD were identified. The frequency of altered latencies, median of latencies in each stage, and correlation between latencies and motor and non-motor clinical features were analyzed. Latencies were considered altered when they were more than two standard deviations from the mean of controls, per age group. Results: It was verified $10 \%$ of alterations in initial stages and $31 \%$ in advanced. There was correlation between latencies and non-motor clinical features. Subjects older than 65, in advanced stages, presented a significant increase of latencies. Conclusion: There was an association between PD severity and P300 prolonged latencies among subjects 65 years old or older.
\end{abstract}

Keywords: P300 component, idiopathic Parkinson's disease, aging, auditory event-related potentials.

\section{RESUMO}

Exames eletrofisiológicos podem fornecer informações sobre o status neurofisiológico na doença de Parkinson (DP). Objetivo: Investigar o prolongamento das latências do P300 auditivo na DP e sua associação com o estágio da doença. Método: Foi avaliado o quadro clínico de 44 pacientes e identificados aqueles em estágio inicial e avançado da DP. Analisou-se a frequência de latências alteradas, mediana das latências em cada estágio e a correlação entre latências e quadro clínico motor e não motor da DP. As latências foram consideradas alteradas quando superiores a dois desvios-padrão da média dos controles, por grupo etário. Resultados: Verificaram-se 10\% de alterações no estágio inicial e 31\% no avançado. Houve correlação entre as latências e o quadro clínico não motor. Sujeitos com mais de 65 anos, em estágio avançado, apresentaram significativo aumento das latências. Conclusão: Existe associação entre gravidade da DP e prolongamento das latências do P300 nos sujeitos acima de 65 anos.

Palavras-chave: P300, doença de Parkinson idiopática, envelhecimento, potenciais evocados auditivos relacionados a eventos.

Parkinson's disease (PD) is a neurodegenerative disorder clinically manifested by rigidity, bradykinesia, rest tremor, and postural instability due to decreased dopaminergic transmission in the substantia nigra pars compacta of the basal ganglia ${ }^{1}$. In addition to the classical motor symptoms, nonmotor disturbances such as cognitive impairment, depression, sleep disorders, and dysautonomies are frequent ${ }^{2}$.

Recent review demonstrated that prevalence of dementia associated to PD is nearly $30 \%$, and cognitive impairment is more frequent late in the course of the disease ${ }^{3}$. However, a slight cognitive deficit was described in early stages ${ }^{4}$. In this way, actual recommendation includes cognitive screening early in the course of the disease ${ }^{5}$.

Generally, cognitive evaluation is performed with neuropsychological tests that require time, and, in some cases, motor abilities, impaired in PD patients. Evoked potentials related to P300 events have been considered useful in the investigation of cognitive status of PD

'Divisão de Neurologia e Epidemiologia, Universidade Federal da Bahia, Salvador BA, Brazil;

${ }^{2}$ Departamento de Fonoaudiologia, Instituto de Ciências da Saúde, Universidade Federal da Bahia, Salvador BA, Brazil.

Correspondence: Marcia da Silva Lopes; Universidade Federal da Bahia; Rua Nita Costa 128/103; 40155-000 Salvador BA - Brasil;

E-mail: marsilopes@yahoo.com.br

Support: Conselho Nacional de Desenvolvimento Científico e Tecnológico (CNPq) and Instituto Nacional de Ciência, Inovação e Tecnologia em Saúde - CITECS. Conflict of interest: There is no conflict of interest to declare.

Received 10 June 2013; Received in final form 16 December 2013; Accepted 07 January 2014. 
patients, as it does not require the execution of motor tasks ${ }^{6,7,8}$.

P300 latency reflects the time required for auditory processing of external stimuli ${ }^{9}$, which increase with the effect of aging on the structures of the nervous system, as well as with the reduction of cognitive capacity in the allocation of attention and memory resources ${ }^{10}$. Thus, elderly patients with PD may present delayed P300 latencies, maybe influenced by the clinical stage of the disease.

Therefore, the objective of this study was to investigate the presence of P300 latency prolongation in DP and its association with the clinical stage of the disease.

\section{METHOD}

\section{Subjects}

This was a descriptive cross-sectional study developed between January and August 2010. The research was approved by the local ethics committee under protocol number 057-2009. All participants signed an informed consent before performing any study procedures.

Patients attending the movement disorders unit were considered eligible if they had a diagnosis of idiopathic PD, according to the United Kingdom Brain Bank ${ }^{11}$. All subjects were under dopaminergic therapy.

Exclusion criteria included history of neurosurgery or other neurological (seizures, head trauma, stroke) and psychiatric diseases (schizophrenia, bipolar disorder, major depression), as these conditions may interfere in P300 results. In addition, subjects with hearing thresholds more than $60 \mathrm{~dB} \mathrm{HL}$ at 1 or $2 \mathrm{kHz}$ frequencies were also excluded.

The control group was formed by age-matched subjects without PD and the same exclusion criteria were applied.

\section{Procedures}

Initially, socio-demographic data including identification, education, past medical history, and hypertension or diabetes treatment were recorded. Also the individuals were evaluated by a Portuguese version of the Mini Mental State Examination (MMSE) scale validated in Brazil' ${ }^{12}$. In the PD group, disease duration was measured as the time since initial diagnosis in years.

Then, subjects were submitted to the audiometry, where hearing thresholds were investigated at the following frequencies: $0.5,1,2,3,4,6$, and $8 \mathrm{kHz}$, in an acoustic enclosure with a calibrated audiometer. In addition, brainstem auditory evoked potentials were evaluated. These measures were performed to observe a possible interference of the auditory level and peripheral neurophysiological conditions in P300 records. All P300 recordings were evaluated by a single trained examiner, blinded to subject group or PD clinical stage.
P300 collection was performed by auditory stimuli presentation according to the oddball paradigm, first in the right side and then in the left side, through $3 \mathrm{~A}$ insertion phones with $80 \mathrm{~dB}$ HL of intensity. Auditory stimuli were presented at $0.8 \mathrm{~s}$ interval, being considered frequent a $1000 \mathrm{~Hz}$ tone (80\%), and rare a $2000 \mathrm{~Hz}$ tone (20\%). Collections were performed with EP25 equipment (Interacoustics), using disposable silver chloride electrodes with impedance below $5 \mathrm{~K} \Omega$ and positioned in regions $\mathrm{A} 1$, $\mathrm{A} 2$, and $\mathrm{Fz}$ according to the 10-20 international system.

All collections showing $95 \%$ of concordance between the number of stimuli presented and the count reported by subjects were considered for analysis.

P300 was identified as the major positive point after P2-N2 complex in tracing of the rare stimulus. Latency analysis for each subject was performed considering the lowest value observed between stimuli presented to the right and the left ear.

P300 test was performed in a comfortable, quiet, and properly illuminated room, with the subject in the supine position and awake. The visual focus of attention was established previously. Subjects were instructed to count silently all the target tones, reporting the total at the end of the session. The test was initiated only when the subject demonstrated a complete understanding of the task. In PD patients, P300 was performed in the "on" state.

Immediately after the P300 test, the subjects were evaluated with the modified Hoehn and Yahr (H\&Y) scale and the Unified Parkinson's Disease Rating Scale (UPDRS) to characterize the clinical profile of the disease.

\section{Statistical analysis}

The frequency and distribution of variables such as gender, diabetes, and hypertension, as well as mean age, and MMSE between PD patients and controls had been described.

To investigate the association between P300 latencies and staging of $\mathrm{PD}$, the frequency of subjects with altered latencies in each $H \& Y$ stage was determined. P300 latency was considered altered when the potential was superior to the PD group mean plus two standard deviations, according to the age group. In addition, a comparison was made between the latencies of patients and the control group data and it was performed the Spearman rank correlation between P300 latencies and UPDRS scores. For the analyses that considered staging according to H\&Y, patients with H\&Y I and II were classified in the initial stage and those with H\&Y III, IV and V, in the advanced stage.

A multivariate analysis ${ }^{13,14}$ was also performed to verify which variables could influence P300 latencies. Therefore, the variables gender, diabetes, hypertension, age range and $\mathrm{PD}$ stage were taken in consideration.

Comparison between groups was performed with the chisquare and Mann-Whitney tests. 
Table 1. Demographic and clinical characteristics of

Parkinson's disease patients and controls.

\begin{tabular}{lccc}
\hline \multirow{2}{*}{ Variables } & \multicolumn{2}{c}{ Groups } & \\
\cline { 2 - 3 } & Controls $(n=33)$ & PD $(n=44)$ & p-value \\
\hline Gender & & & \\
$\quad$ Male & $05(15.2 \%)$ & $24(54.5 \%)$ & $0.001^{\mathrm{c}}$ \\
$\quad$ Female & $28(84.8 \%)$ & $20(45.5 \%)$ & \\
Age & $60(56-69)^{\mathrm{a}}$ & $64(55-71)^{\mathrm{a}}$ & $0.378^{\mathrm{d}}$ \\
$\quad 48-65$ & $58(54-61)^{\mathrm{a}}$ & $56(53-62)^{\mathrm{a}}$ & $0.654^{\mathrm{d}}$ \\
$\quad 66-81$ & $72(69-74)^{\mathrm{a}}$ & $73(68-78)^{\mathrm{a}}$ & $0.580^{\mathrm{d}}$ \\
Diabetes & $04(12.1 \%)$ & $05(11.4 \%)$ & $0.918^{\mathrm{c}}$ \\
Hypertension & $15(44.5 \%)$ & $23(52.3 \%)$ & $0.554^{\mathrm{c}}$ \\
MMSE & & & \\
Cognitive deficit & 0 & $03(6.8 \%)$ & $0.126^{\mathrm{c}}$ \\
\hline
\end{tabular}

aMedian (Percentile 25-75); ' Mini Mental State Examination; 'Pearson Chi-square; 'Mann-Whitney.

\section{RESULTS}

Demographics and clinical characteristics of PD subjects and controls are shown in Table 1.

The mean disease duration among PD subjects was 7 years $( \pm 6)$. As to the disease's clinical stage, there were 9 patients in H\&Y I (20.5\%), 19 in H\&Y II (43.2\%), 10 in H\&Y III (22.7\%), 5 in H\&Y IV (11.4\%), and 1 in H\&Y V (2.3\%). Twenty eight subjects were classified as early-stage PD (63.6\%) and $16(36 \%)$ as advanced-stage PD. The mean total UPDRS score was $56.11( \pm 28.90)$, distributed as follows: $3.02( \pm 2.32)$ in UPDRS I, $15.84( \pm 10.46)$ in UPDRS II, 32.11 $( \pm 19.38)$ in UPDRS III, and $3.68( \pm 2.87)$ in UPDRS IV.

P300 latency was not detected in one PD patient, and he was excluded from analysis. P300 latencies in PD patients (median 358; P25 324; P75 388) were significantly delayed $(\mathrm{p}=0.023)$ when compared to normal controls (median 336; P25 304; P75 358).

Table 2 shows the distribution of P300 latencies and the frequencies of subjects with abnormal results, according to the modified H\&Y stages and the classification in early or advanced PD.

The distribution of P300 latencies among patients and controls, considering the age group are presented

Table 2. P300 latency distribution and frequency of altered results in Parkinson's disease group (PD).

\begin{tabular}{lcccc}
\hline \multirow{2}{*}{ Stages* $^{*}$} & \multicolumn{4}{c}{ P300 latencies } \\
\cline { 2 - 5 } & \multicolumn{3}{c}{ Measures $^{\text {a }}$} & \multicolumn{2}{c}{ Alterations $^{\mathbf{b}}$} \\
\hline H\&Y I & 347 & $(316-383)$ & 1 & $(11.11)$ \\
H\&Y II & 344 & $(312-370)$ & 3 & $(15.79)$ \\
H\&Y III & 376 & $(345-441)$ & 3 & $(30.00)$ \\
H\&Y IV & 350 & $(335-441)$ & 2 & $(40.00)$ \\
H\&Y V & 374 & $(374)$ & 0 & $(0.00)$ \\
Early PD & 344 & $(314-370)$ & 3 & $(10,71)$ \\
Advanced PD & 375 & $(347-440)$ & 5 & $(31.30)$ \\
\hline
\end{tabular}

*Stages according to Hoehn and Yahr; ${ }^{a}$ Median (Percentile 25-75);

${ }^{b}$ Frequency of subjects with altered latencies (percentage); 'Hoehn and

Yahr stages I and II; 'Hoehn and Yahr stages III, IV and V.

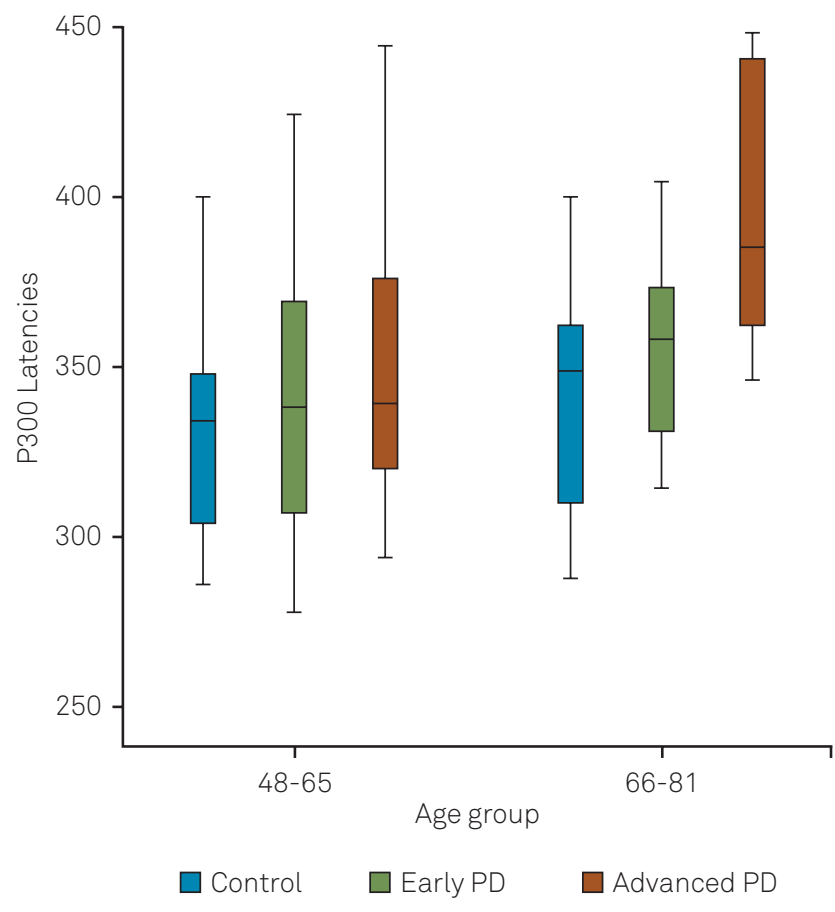

* $\mathrm{p}<0.05$ : Control x Advanced PD; Early PD x Advanced PD. PD: Parkinson's disease.

Figure. P300 latency distribution between groups, according to age.

in Figure. In the 48 to 65 age group were analyzed 23 controls, 19 patients in PD early group, and six in PD advanced. In subjects aged 66 to 81 years were analyzed 10 controls, eight patients in PD early group, and 10 in PD advanced.

In the 66 to 81 age group, there was a significant difference between PD patients and controls $(\mathrm{p}=0.037)$, controls and advanced PD $(\mathrm{p}=0.011)$, and early PD and advanced $\mathrm{PD}(\mathrm{p}=0.045)$. In subjects aged 48 to 65 years, P300 latencies were similar in all groups.

It was only observed a significant positive correlation between P300 latencies and UPDRS I ( $\mathrm{rs}=0.396 ; \mathrm{p}=0.009)$ and II ( $\mathrm{rs}=0.401 ; \mathrm{p}=0.008$ ).

Multivariate analysis revealed that normal P300 latency is associated with the age group from 48 to 65 years and early PD. On the other hand, altered P300 latency is associated with the age group from 65 to 81years and advanced PD. There was no association between P300 latency and the variables gender, hypertension and diabetes.

\section{DISCUSSION}

Our data show that PD patients in the advanced stages and over 65 years have prolonged P300 latencies. These results, in addition to reinforcing the influence of PD severity in P300 latencies, demonstrate the synergy between aging 
and the neurodegenerative process in non-dopaminergic structures related to cognition.

The natural aging process is a major factor in the biochemical and histopathological changes in the nervous system structures that participate in cognitive processes ${ }^{15,16}$. In patients with $\mathrm{PD}$, these changes are more pronounced ${ }^{17}$ and correlate with disease severity ${ }^{3}$. This information allows us to speculate that the histopathological changes observed in Parkinson's disease can be emphasized by the natural aging process. Thus we can interpret the increase of P300 latency as a marker of this phenomenon, which becomes more significant in PD patients over 65 years of age.

Our findings support the study ${ }^{18}$ which describes the age as a factor strongly related to P300 latencies in PD and for this reason, we believe that comparisons between groups of subjects should consider more restricted age groups. While we observed latency prolongation related to the severity of the disease in elderly people over 65 years old, we also verified that in younger subjects there is no significant retardation in the generation of the potential even in more severe PD clinical features. In this way, we verified that the behavior of latencies differ according to the age groups. This premise is reinforced by the conclusions of previous study ${ }^{19}$, which did not observe increase of P300 latencies associated to the evolution of PD. We can observe that in this study ${ }^{19}$ latencies obtained from groups of subjects with broad age ranges were compared, making us believe that this might be a factor that contributed to the dispersion of latency values among the groups, producing results, somewhat, divergent from ours.

In addition to the contribution of aging to latency prolongation, it should be stressed that in the advanced stages of PD, there is an increase in the frequency and intensity of cognitive impairment ${ }^{3}$, possibly due to dysfunction of structures related to cognition, such as the limbic system, temporal mesocortical areas, and neocortical association $\operatorname{areas}^{20}$. On the other hand, in the early stages of PD, cognitive impairment is slight and less prevalent ${ }^{21,22}$, this could explain the reduced number of subjects in this stage with delayed P300 latencies.

As well as in other studies ${ }^{7,18}$, we observed that P300 latency does not correlate with motor function when evaluated in details by UPDRS part III. This piece of information is suitable with the fact that there are different dopaminergic pathways related to motor and mental impairment in $\mathrm{PD}^{23}$, emphisizing that dopaminergic areas are also involved in cognitive decline $\mathrm{e}^{20,16}$. It is also convenient to consider that UPDRS III can attribute similar scores to subjects in different clinical stages.

Nevertheless, we observed a positive correlation between P300 latencies and UPDRS I and II scores. UPDRS I scores evaluates losses in mental functions (mentation, behavior and mood) that influence the generation of $\mathrm{P} 300^{10,24}$. Previous studies have shown a positive correlation between the prolongation of P300 latencies in PD and deficits in memory, attention, executive functions, and depression $^{6,725,26}$. The authors suggest that prolonged P300 latencies are correlated to cognitive impairment ${ }^{7}$ and behavioral problems $^{27}$ in PD patients.

It is possible to hypothesize that the correlation found between UPDRS II and P300 latencies could be explained by the participation of attention and executive functions in planning and executing daily tasks, even taking into account the strong influence of motor performance in activities of daily living. Our results are in accordance with a previous study $^{26}$ that showed association between a bigger score in UPDRS part II and cognitive losses in individuals with PD.

Our data suggest that P300 auditory latencies could be used to follow up the evolution of PD; nevertheless, limitations of this tool concerning the determination of specific clinical status should be considered.

In conclusion, our data demonstrated that PD subjects over 65 years old have prolonged P300 latencies when compared to normal controls and this prolongation is more emphasized in individuals in advanced stages of the disease.

\section{References}

1. Tolosa E, Wenning G, Poewe W. The diagnosis of Parkinson's disease. Lancet Neurol 2006;5:75-86.

2. Chaudhuri KR, Healy DG, Schapira HVA. Non-motor symptons of Parkinson's disease: diagnosis and management. Lancet Neurol 2006;5:235-245.

3. Aarsland D, Kurz MW. The epidemiology of dementia associated with Parkinson disease. J Neurol Sci 2010;289:18-22.

4. Aarsland D, Bronnick K, Williams-Gray C, et al. Mild cognitive impairment in Parkinson disease: a multicenter pooled analysis. Neurology 2010;75:1062-1069.

5. Peavy GM. Mild cognitive deficits in Parkinson disease: where there is bradykinesia, there is bradyphrenia. Neurology 2010;75:1038-1039.

6. Chen KJ, Lin RT, Liu CK, Tai CT, Lai CL. Relationship between eventrelated potentials and frontal-subcortical dyfunction in Parkinson's disease. Parkinsonism Relat Disord 2006;12:453-458.
Matsui H, Nishinaka K, Oda M, Kubori T, Udaka F. Auditory eventrelated potentials in Parkinson's disease: Prominent correlation with attention. Parkinsonism Relat Disord 2007;13:394-398.

8. Naskar S, Sanjay SK, Goyal V. Effect of acute deep brain stimulation of the subthalamic nucleus on auditory event-related potentials in Parkinson's disease. Parkinsonism Relat Disord 2010;16:256-260.

9. Magliero A, Bashore T, Coles M, Donchin E. On the dependence of P300 latency on stimulus evaluation processes. Psychophysiology 1984;21:171-186.

10. Polich J. Updating P300: an integrative theory of P3a and P3b. Clin Neurophysiol 2007;118:2128-2148.

11. Hughes AJ, Daniel SE, Kilford L, Lees AJ. Accuracy of clinical diagnosis of idiopathic Parkinson's disease: a clinico-patological study of 100 cases. J Neurol Neurosurg Psychiatr 1992;55:181-184. 
12. Almeida OP. Mini Exame do Estado Mental e o diagnóstico de demência no Brasil. Arq Neuropsiquiatr 1998;56:605-612.

13. Pereira JCR. Análise de dados qualitativos. EdUSP. 1999.

14. Dray S, Dufour AB. The ade4 package: implementing the duality diagram for ecologists. J Statistic Soft 2007;22:6.

15. Ubhia K, Penga K, Lessiga S, et al. Neuropathology of dementia with Lewy bodies in advanced age: a comparison with Alzheimer disease. Neuroscience Letters 2010;485:222-227.

16. Emre M. What causes mental dysfunction in Parkinsonás Disease? Mov Disord 2003;18(Suppl 6);S63-S71.

17. Krishnan S, Sarma G, Sarma S, Kishore A. Do nonmotor symptoms in Parkinson's disease differ from normal aging? Mov Disord 2011;26:2110-2113.

18. Stanzione P, Semprini R, Pierantozzi M, et al. Age and stage dependency of P300 latency alterations in non-demented Parkinson's disease patients without therapy. Electroencephalogr Clin Neurophysiol 1998;108:80-91.

19. Tsuchiya H, Yamaguchi S, Kobayashi S. Impaired novelty detection and frontal lobe dysfunction in Parkinson's disease. Neuropsychologia 2000;38:645-654.

20. Braak H, Del Tredici K, Rüb R, de Vos RAl, Jansen Steur ENH, Braak E. Staging of brain pathology related to sporadic Parkinson's disease. Neurobiol Aging 2003;24:197-211.
21. Uc EY, McDermot MP, Marder KS, et al. Incidence of and risk factors for cognitive impairment in an early Parkinson disease clinical trial cohort. Neurology 2009;73:1469-1477.

22. Williams-Gray CH, Foltynie T, Brayne CEG, Robbins TW, Barker RA. Evolution of cognitive dysfunction in an incident Parkinson's disease cohort. Brain 2007;130:1787-1798.

23. Brussoulle E, Dentresangle $C$, Landais $P$, et al. The relation of putamen and caudate nucleus 18F-Dopa uptake to motor and cognitive performances in Parkinson's disease. J Neurol Sci 1999;166:141-151

24. Pogarell O, Padberg F, Karch S, et al. Dopaminergic mechanisms of target detection - P300 event related potential and striatal dopamine. Psychiatry Res: Neuroimaging 2011;194:212-218.

25. Nojszewska M, Pilczuk B, Zakrzrwska-Pniewska B, RowinskaMarcinska K. The auditory system involvment in parkinson disease: electrophysiological and neuropsychological correlations. J Clin Neurophysiol 2009;26:430-437.

26. Weintraub D, Moberg PJ, Duda JE, Katz IR, Stern MB. Effect of psychiatric and other nonmotor symptoms on disability in Parkinson's disease. J Am Geriatr Soc 2004;52:784-788.

27. Chia LG, Cheng LJ, Chuo LJ, Cheng FC, Cu JS. Studies of dementia, depression, electrophysiology and cerebrospinal fluid monoamine metaboities in patients with Parkinson's disease. J Neurol Sci 1995;133:73-78. 